\title{
APROXIMACIONES HISTÓRICAS Y ARQUEOLÓGICAS A LA OCUPACIÓN INKA Y LOS CAMINOS PREHISPÁNICOS DE LEVANTO (AMAZONAS, PERÚ) ${ }^{1}$
}

\author{
HISTORICAL AND ARCHAEOLOGICAL APPROACHES TO THE INKA \\ OCCUPATION AND PREHISPANIC ROADS OF LEVANTO (AMAZONAS, PERU)
}

\author{
Carlos E. Campos Napán ${ }^{2}$
}

\begin{abstract}
Si bien la ocupación inka en la región de los chachapoyas ha sido estudiada por varios especialistas, los estudios arqueológicos se han centrado en investigar el imponente sitio de Kuélap en Luya, el sitio de Cochabamba en Chuquibamba, y la Laguna de Los Cóndores en la frontera de los departamentos de Amazonas y San Martin, sin tratar de manera más exhaustiva la ocupación inka y el sistema vial de una zona con abundante evidencia arqueológica, como lo es el distrito de Levanto. El presente ensayo se centrará en caracterizar Levanto, un antiguo centro prehispánico que jugó un importante rol durante el periodo inka. El estudio se apoya en la documentación etnohistórica revisada, algunos informes inéditos y nuestros reconocimientos arqueológicos.
\end{abstract}

Palabras claves: caminos prehispánicos, documentación etnohistórica, chachapoyas, inkas.

Although the Inka occupation in the Chachapoyas region has been studied by several specialists, the archaeological studies have focused on the imposing site of Kuélap in Luya, the Cochabamba site in Chuquibamba, and the Laguna de Los Cóndores on the border of the departments of Amazonas and San Martin. However, they have not dealt comprehensively with the Inka occupation and the road system of the Levanto district, with its plentiful archaeological evidence. This essay aims to characterize Levanto, an ancient pre-Hispanic center, which played an important role during the Inka period. The study is supported by reviewed ethnohistorical documentation, some unpublished reports, and our archaeological expeditions.

Key words: Prehispanic roads, ethnohistorical documentation, Chachapoyas, Inka.

En la región denominada y conocida como Amazonas en el norte del Perú, se desarrolló una de las civilizaciones más singulares y asombrosas de esta parte de los Andes, como lo fue la de los célebres chachapoyas (900-1470 DC), que abarcó un área geográfica particular conocida como ceja de selva o selva alta. Esta sociedad anterior a los inkas se caracterizó por edificar construcciones de planta circular en zonas inexpugnables y de difícil acceso, siendo otro de los logros de tan particular sociedad la construcción de imponentes mausoleos tipo chullpa y sarcófagos erigidos en los acantilados de tan agreste geografía.
La región que dominaban, conocían y manejaban los chachapoyas, fue una zona productiva de gran valor desde el punto de vista económico y preciada por algunos productos suntuosos, por lo que, fue atrayente para los soberanos cusqueños quienes, según los relatos dejados por cronistas hispanos y mestizos, emprendieron la conquista de tan inexpugnable y agreste región alrededor de 1470 DC. Seguramente la zona les resultó muy similar a la selva alta de Vilcabamba cercana al Cusco, en cuanto a recursos naturales y clima, pero, sin duda, otra de las razones para apropiarse de ella fue el hecho de que este territorio contaba con

\footnotetext{
${ }^{1}$ Una primera versión de este trabajo fue presentada en el Qhapaq Nan II, Taller Internacional en torno al Sistema Vial Inkaico (24-27 de octubre de 2017), efectuado en Salta, Argentina. Este manuscrito fue evaluado por pares externos y editado por el Comité Editorial de Chungara y los editores invitados Carlos González y Christian Vitry.

${ }^{2}$ Ministerio de Cultura del Perú, Qhapaq Ñan- Sede Nacional, Lima, Perú. carlos5bn@ hotmail.com
} 
una numerosa población, bien organizada y que conocía adecuadamente esta región compleja de los Andes.

Inge Schjellerup (2002), estudiosa de los chachapoyas, refiere que:

La palabra "Chachapoya" es probablemente una construcción de los incas, compuesta de la palabra "chacha" -tomada del nombre de uno de los subgrupos llamados chacha que vivía en Levanto, donde Túpac Inca Yupanqui dejó descendientes- y la palabra quechua "puyu", que significa 'nube' o 'nublado' (Schjellerup 2002:48).

Desde estas consideraciones iniciales, el presente trabajo se centra en el estudio de la ocupación inka y los caminos prehispánicos de Levanto, antiguo centro chachapoya en Los Andes nororientales del Perú, cuyas características se definen a continuación.

\section{Área de Estudio}

El área de estudio se localiza políticamente en el departamento de Amazonas, provincia de Chachapoyas, entre los distritos de San Juan de la Frontera de los Chachapoyas y San Pedro de Levanto (Figura 1).

El distrito de Levanto se encuentra a $20 \mathrm{~km}$ al suroeste de la ciudad de Chachapoyas, capital del departamento de Amazonas, oscilando la variación altitudinal del distrito entre $2.300 \mathrm{msm}$ y $3.500 \mathrm{msm}$.

El relieve de Levanto es abrupto y accidentado, con fuertes pendientes en las partes altas e inclinaciones medias en las partes bajas. Levanto pertenece, según la clasificación de ecorregiones señalada por Brack (2006), a la selva alta o Andes amazónicos de acuerdo a Federico Kauffmann (Kauffmann 2013; Kauffmann y Ligabue 2003). Levanto presenta un clima templado frío con una temperatura media que oscila entre los 11 y 16 grados centígrados, y se caracteriza por constantes precipitaciones pluviales durante casi todo el año, que favorecen la producción agrícola y el pastoreo, gracias al follaje para el alimento del ganado vacuno. Esta ecorregión, además, cuenta con una flora muy variada, al igual que una fauna muchas veces endémica (Campos 2008).

El poblador actual de Levanto diferencia dos estaciones: invierno, caracterizada por la lluvia (meses de octubre a abril), y verano, con meses secos y notable brillo solar (meses de mayo a septiembre); sin embargo, debido a las condiciones actuales de deforestación del paisaje expresada en la excesiva tala y quema de vegetación, las condiciones climáticas han variado considerablemente, siendo en la actualidad muy difícil de predecir la duración de las temporadas secas y lluviosas.
Los factores ambientales del paisaje determinaron muchas veces la localización, traza y construcción de los sitios y caminos prehispánicos. Dichos factores son variables, a causa de las diversas zonas ecológicas existentes dentro del accidentado territorio peruano, las cuales han ejercido un notable efecto en la ingeniería adoptada para la elaboración de la infraestructura, no solo de los edificios sino también del sistema vial. Todo ello se torna evidente al observar las diversas formas, adaptaciones y creaciones realizadas a lo largo y ancho del Qhapaq Ñan; el famoso Camino del Inka o Qhapaq Nan, relatado y admirado por los cronistas, que trascendió a los ojos del mundo al ser comparado con las vías romanas.

\section{Documentación Etnohistórica}

\section{Los Chachapoyas}

Las crónicas españolas señalan los denodados esfuerzos que los ejércitos del Inka tuvieron que realizar para someter a los aguerridos y rebeldes chachapoyas, primero durante el gobierno de Inka Túpac Yupanqui (Cabello de Valboa 1951 [1586]; Cieza de León 1986 [1553]; Garcilaso de la Vega 1991 [1609]), luego durante el gobierno de Wayna Qhapaq, rebelándose en dos oportunidades (Cieza de León 1986 [1553]; Garcilaso de la Vega 1991 [1609]), y finalmente durante la última victoria de los ejércitos inkas en territorio chachapoyas para controlar la sublevación de los pomacochas, mientras gobernaba Waskar (Murúa 2001 [1613]). No obstante, se señala también que 1.200 chachapoyas y cañaris fueron utilizados como "alabarderos y lacayos" del emperador Waskar (Schjellerup 2002, 2005). Complementariamente, los inkas intentaron doblegar a esta población rebelde trasladándolos en por lo menos 26 grupos de mitmaqkuna a diferentes latitudes del Tawantinsuyu, según detalla Inge Schjellerup (2017:264).

El conjunto de esta información nos hace preguntarnos, ¿cuál era el interés de los inkas en el territorio de los chachapoyas, y su firme idea de tenerlo bajo su dominio?

Entre los arqueólogos e historiadores que han descrito y discutido sobre los chachapoyas, hay un cierto consenso en señalar que fue un conjunto de curacazgos, ayllus y/o parcialidades que formaban parte de un mismo grupo étnico, que los inkas denominaron chachas o chachapoyas, nombre tomado de uno de los curacazgos que conformaban este extenso grupo cultural del nororiente peruano. En las crónicas hispanas se describe a los chachapoyas como "gente de guerra", sin embargo, no solo eran conocidos como valientes guerreros, sino también como inteligentes agricultores, talentosos tejedores, hechiceros o chamanes, médicos 


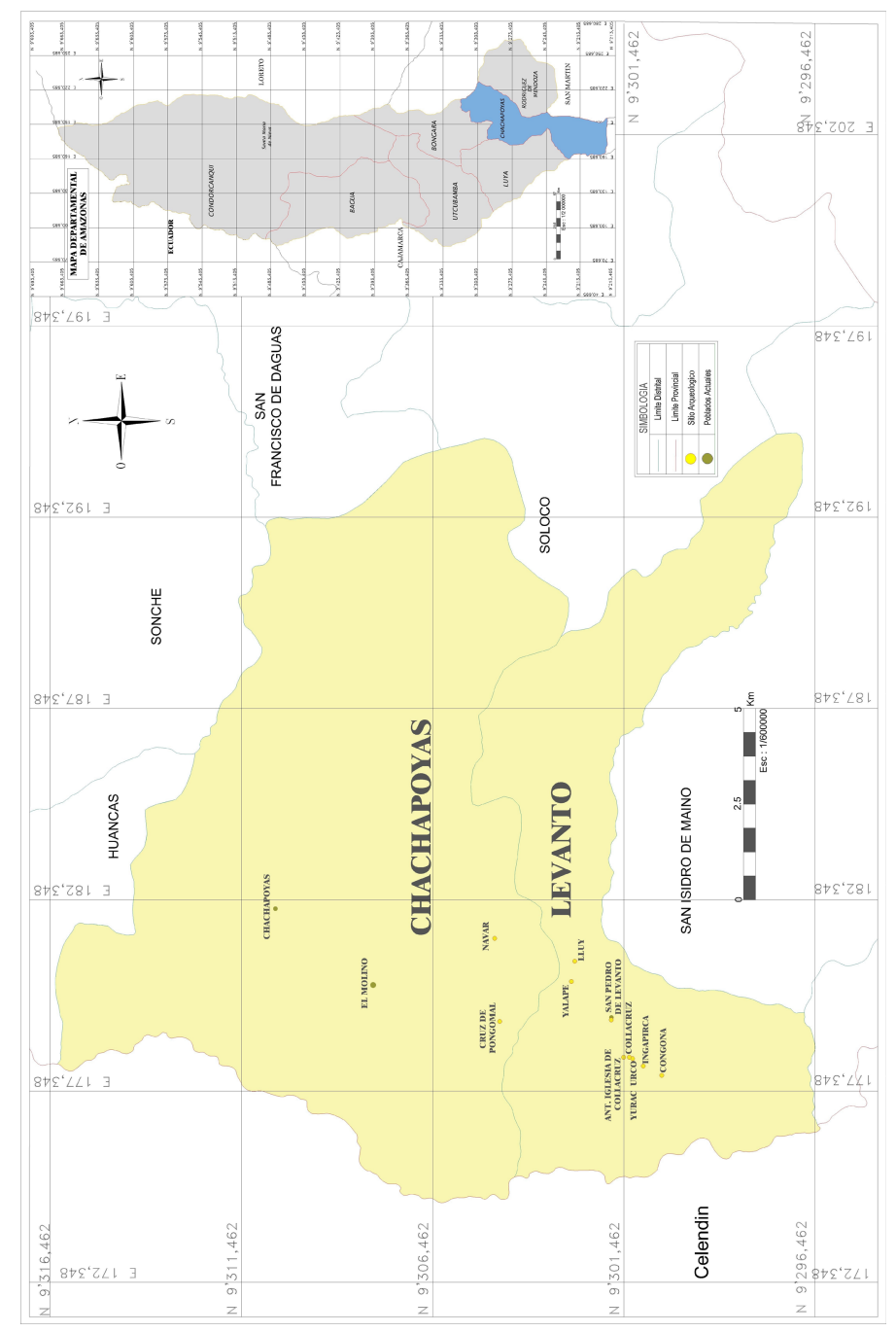


de hierbas y constructores de puentes (Schjellerup 2005).

Tal vez una respuesta a la interrogante planteada pueda hallarse en que los chachapoyas se constituían en una población numerosa, donde los hombres estaban provistos para la guerra, conocedores de su medio ambiente y buenos constructores en piedra, y quizás por ello los inkas persistieron en su afán de subyugarlos.

\section{Levanto, Llauantu, Llahuantu o Llehuanto}

De acuerdo a Espinoza (1967), Llehuanto fue el centro inka más importante dentro del territorio Chachapoyas. Para Davis (1996:226), Llauantu es uno de los siete curacazgos chachapoyas nombrados en la crónica de Garcilaso de la Vega, señalando que este fue el curacazgo chachapoyas más importante.

En su trabajo pionero sobre los chachapoyas, el historiador alemán Peter Lerche (1995), valiéndose de datos etnohistóricos y arqueológicos, establece algunas características propias de este grupo cultural, considerando:

Al curacazgo preinca de Levanto como el de mayor extensión con $250 \mathrm{~km}^{2}$, que posteriormente durante la época inca se transformaría en la sede principal de la provincia inca de los Chachapoya (Lerche 1995:95).

Asimismo, el historiador Waldemar Espinoza utiliza el término Llehuantu y Llehuanto indistintamente, para referirse a esta llaqta siempre mencionada como un centro chachapoyas donde los inkas erigieron una instalación, un palacio y un templo del sol (Espinoza 1967:231, 237, 239).

\section{Siguiendo a Peter Lerche,}

[...]ya sea que el topónimo Levanto formaba parte del complejo idiomático preincaico de la zona, o haya sido introducido por los incas [...], en ambas posibilidades podría ser que la traducción de Levanto era: lugar de varones fuertes (Lerche 1995:29).

Lerche destaca, igualmente, que: "los incas escogieron Levanto como su sede principal no sólo por aspectos de culto, sino también por su posición estratégica dentro de un complejo macro económico" (Lerche 1995:95).

Del mismo modo, en el Primer Libro de Cabildo de San Juan de la Frontera de los Chachapoyas se indica que: "[...] en este pueblo ay un boyo Redondo blanco en donde los dichos yngas E señores solían hacer sus sacreficios al sol [...]" (Rivera Serna 1955:304).
Esta aseveración podría ser un argumento más para afirmar que existieron estructuras inkas de carácter religioso en Levanto.

Cuando el imperio Inka cayó tras la captura del Inka Atawallpa, los chachapoyas fueron uno de los primeros grupos en abrazar la causa hispana, gracias a ello no fue sino hasta 1538 que los españoles deciden fundar una ciudad. El cronista Pedro Cieza de León nos refiere, sobre la entrada de los españoles en territorio chachapoyas y la fundación española de la ciudad, señalando que:

En los pueblos de esta provincia de los chachapoyas entró el capitan Alonso de Albarado [...] El cual después que hubo conquistado la provincia y puestos los indios naturales debajo del servicio de su majestad pobló y fundó la ciudad de la Frontera en un sitio llamado Levanto, lugar fuerte y que con los picos y azadones se allanó para hacer la población [...] (Cieza de León 1984 [1553]:192).

Otro dato histórico relevante señalado por los investigadores, es que la ciudad de Chachapoyas fue el lugar donde se instalaron los españoles, con la intención de que fuera el punto de partida para continuar con las conquistas hacia el oriente del Perú, tras la búsqueda de El Dorado o El Paititi (Kauffmann 2013; Ruiz 2010).

Desde los relatos dejados en las crónicas hispanas que han llegado hasta nuestros días, afirmamos que Levanto fue primero un antiguo asentamiento de los chachapoyas, el que posteriormente, durante la ocupación inka, se transformó en un importante sitio, siendo la capital de una de las provincias de los chachapoyas bajo dominio inkaico. Finalmente, fue tomado y convertido en el segundo emplazamiento de la ciudad fundada por los españoles, denominada San Juan de la Frontera de los Chachapoyas, en setiembre de 1538.

\section{Antecedentes Arqueológicos}

Un antiguo antecedente de la zona de estudio es la excavación del sitio de San Pedro de Huashpa (Huallpa), localizado en Levanto, por parte de los esposos Reichlen, a fines de la década de 1940; aunque los datos que presentan son muy escuetos (Reichlen y Reichlen 1950).

Posteriormente, el arqueólogo canadiense Morgan Davis $(1988,1996)$ realizó trabajos en el distrito de Levanto y en toda la provincia de Chachapoyas, describiendo los lugares y sitios arqueológicos más importantes como Kuélap, Leimebamba, La Jalca Grande y Levanto; además, dejo entrever la existencia de caminos en todo el territorio de los chachapoyas. Asimismo, Davis (1996) en 1992 dirigió la restauración de la estructura circular 
de Yurac Urco, en el anexo de Collacruz del distrito de Levanto, colocándose un techo cónico de paja, que es el primer ensayo de restauración alusivo a los techados de los antiguos chachapoyas en la región.

El año 2003, el equipo Qhapaq Ñan de aquella temporada realizó trabajos en el distrito de Levanto, localizando dos de los cuatro tramos de camino inka reportados por nosotros y algunos asentamientos, entre los que destaca uno, conocido como la antigua iglesia de Collacruz, que el equipo en mención denominó el "tambo de Levanto" (Montoya et al. 2003:21).

La Dirección de Estudios sobre Paisaje Cultural, del entonces Instituto Nacional de Cultura (hoy Ministerio de Cultura), en el 2006 dedicó un pequeño volumen al Qhapaq Ñan registrado entre la localidad de Pías en la región de La Libertad, y Chachapoyas, capital de la región Amazonas, buscando plasmar la organización actual del territorio y evaluar la organización territorial en torno al Qhapaq Ñan subsistente (Caja y Díaz 2006). En este trabajo se proporcionan algunos datos importantes con respecto al levantamiento de información geográfica del distrito de Levanto, y el estado actual del camino inka en dicha jurisdicción y las aledañas.

En el 2008 formamos parte del equipo de Inventario y Registro de Sitios Arqueológicos del Instituto Nacional de Cultura (actual Ministerio de Cultura), asignado a la región Amazonas. En esa oportunidad realizamos dos salidas, que incluyeron los distritos de Levanto y San Isidro del Mayno (Campos 2008), en las que registramos e identificamos un total de 49 sitios de diferentes periodos prehispánicos, además de incluir sitios asignados a periodos posteriores a la irrupción hispana.

Debido a la cantidad de sitios adscritos al Intermedio Tardío (900 - 1470 DC) y Horizonte Tardío (1470 - 1532 DC), es que decidimos emprender otros reconocimientos para recabar mayor información concerniente a definir la estrategia empleada por los inkas en la conquista de este agreste territorio (Bolaños 2017; Campos 2017).

\section{Metodología}

En las prospecciones que hemos llevado a cabo en la zona (Bolaños 2017; Campos 2008, 2017), se contempló el recorrido de los caminos, utilizando un GPS Garmin Etrex 20 y algunas fotos obtenidas de la plataforma virtual Google Earth. Durante el desarrollo de las exploraciones arqueológicas se tomaron fotografías de los caminos y se realizaron algunas medidas, junto con efectuar un registro detallado de los elementos arquitectónicos que los conforman, a partir del llenado de fichas. Los caminos fueron registrados siguiendo las unidades de sectorización para la identificación y registro de caminos propuesta en la Guía de Identificación del Qhapaq Nan (Bar et al. 2016; Ministerio de Cultura 2013), en donde se discuten los términos de tramo, sub-tramo, segmento y sección para el caso peruano. Se debe considerar, además, que una de las formas para lograr identificar el periodo al que pertenecen los caminos es a través del reconocimiento y registro de asentamientos, estructuras y/o elementos asociados a estas vías; para lo cual es necesario tener en cuenta y reconocer las formas arquitectónicas más frecuentes del patrón constructivo inkaico, así como determinar la diferencia de estas formas con la etnia local precedente (Hyslop 1992). En nuestro caso, la planta circular de los edificios es de filiación chachapoyas, mientras que la planta rectangular es de asignación inka (Narváez 1988). Sin embargo, los caminos que a continuación presentamos se encuentran cubiertos a la redonda por vegetación arbórea y herbácea, que dificulta la visibilidad de los asentamientos. De igual manera, debemos señalar que estos caminos fueron utilizados durante el Virreinato y gran parte del periodo Republicano, por lo que tampus o chasquiwasis pudiesen haber sido dañados o modificados por afectaciones que son difíciles de apreciar en la actualidad (Bolaños 2017). En esta oportunidad, por cuestiones de espacio, nos restringiremos a proporcionar información de los caminos de Levanto y de solo 10 sitios arqueológicos relacionados, gravitantes dentro de nuestra investigación (Tabla 1).

Tabla 1. Departamento de Amazonas, provincia de Chachapoyas: lista de sitios arqueológicos mencionados en el texto.

Department of Amazonas, Province of Chachapoyas: list of archaeological sites mentioned in the text.

\begin{tabular}{lccccl}
\hline \multicolumn{1}{c}{ Sitio } & Distrito & $\begin{array}{r}\text { Altura } \\
(\mathrm{msm})\end{array}$ & $\begin{array}{c}\text { Area } \\
\left(\mathrm{m}^{2}\right)\end{array}$ & $\begin{array}{c}\text { Cronología } \\
\text { relativa }\end{array}$ & Tipo de sitio \\
\hline Yálape & Levanto & 2.950 & 100.000 & $\begin{array}{l}\text { Chachapoyas, } \\
\text { Inka }\end{array}$ & Asentamiento \\
\hline $\begin{array}{l}\text { Yurac- } \\
\text { Urco }\end{array}$ & Levanto & 2.668 & 250 & $\begin{array}{l}\text { Chachapoyas, } \\
\text { Inka }\end{array}$ & $\begin{array}{l}\text { Estructura } \\
\text { aislada }\end{array}$ \\
\hline Navar & Chachapoyas & 2.880 & 120.000 & Chachapoyas & Asentamiento \\
\hline Lluy & Levanto & 2.724 & 30.000 & Chachapoyas & Asentamiento \\
\hline $\begin{array}{l}\text { Ingapirka } \\
\text { Levanto }\end{array}$ & 2.659 & 20.000 & $\begin{array}{l}\text { Chachapoyas, } \\
\text { Inka }\end{array}$ & Asentamiento \\
\hline $\begin{array}{l}\text { Antigua } \\
\text { Iglesiade } \\
\text { Collacruz }\end{array}$ & Levanto & 2.682 & 5.000 & Inka & $\begin{array}{l}\text { Estructuras } \\
\text { aisladas }\end{array}$ \\
\hline $\begin{array}{l}\text { San } \\
\text { Pedro de } \\
\text { Levanto }\end{array}$ & Levanto & 2.600 & 80.000 & Inka, Colonial & Asentamiento \\
\hline $\begin{array}{l}\text { Collacruz } \\
\text { Congona }\end{array}$ & Levanto & 2.671 & 10.000 & Inka & Asentamiento \\
\hline $\begin{array}{l}\text { Cruzde } \\
\text { Pongomal }\end{array}$ & Levanto & 2.580 & 50 & Inka & $\begin{array}{l}\text { Estructura } \\
\text { Aislada }\end{array}$ \\
\hline & 2.638 & 350 & Inka & Altar $/ U$ shnu \\
\hline
\end{tabular}

\section{Descripción de los Caminos de Levanto}

Antes de llegar a esta provincia de Caxamalca, sale un camino que también fue mandado hacer por los reyes Ingas, por el cual se iba a las provincias de los chachapoyas. Y pues en la comarca de ellas está poblada la ciudad de la Frontera [... (Cieza de León 1984 [1553]:191). 
En Levanto se identificaron un subtramo y tres subsecciones de caminos prehispánicos, teniendo como eje central el centro poblado de Levanto (Tabla 2), lo que nos podría estar señalando la planificada presenciainkaica en un área dominada anteriormente por la "macroetnia de los chachapoya" (Kauffmann y Ligabue 2003). Una característica fundamental de los caminos en esta zona está representada por las pendientes cuesta arriba y cuesta abajo, combinadas con pendientes laterales. Igualmente, durante el recorrido de estos caminos pudimos identificar varios canales de drenaje del tipo abierto, descritos por otros investigadores (Hyslop 1992:217). Los sistemas de drenaje son una tecnología constructiva bastante usual de ser hallada en los caminos empedrados, "[...] dado que el empedrado, es en sí mismo una técnica empleada para proteger la superficie del camino del exceso de agua" (Hyslop 1992:218).

Tabla 2. Características de los caminos prehispánicos de Levanto.

Characteristics of the Prehispanic roads of Levanto.

\begin{tabular}{|c|c|c|c|c|}
\hline $\begin{array}{c}\text { Caminos } \\
\text { prehispánicos }\end{array}$ & $\begin{array}{l}\text { Longitud } \\
(\mathrm{km})\end{array}$ & $\begin{array}{l}\text { Ancho } \\
(\mathrm{m})\end{array}$ & Sectorización & $\begin{array}{c}\text { Componentes } \\
\text { arquitectónicos }\end{array}$ \\
\hline $\begin{array}{l}\text { Levanto - } \\
\text { El Molino } \\
\text { El Molino - } \\
\text { Chachapoyas }\end{array}$ & $\begin{array}{c}9,5 \\
2\end{array}$ & $\begin{array}{c}2,5-4 \\
2,5\end{array}$ & Subtramo & $\begin{array}{l}\text { Calzada empedrada } \\
\text { Escalinatas de piedra } \\
\text { Canales de drenaje } \\
\text { Cunetas } \\
\text { Muros de } \\
\text { sostenimiento o de } \\
\text { contención }\end{array}$ \\
\hline $\begin{array}{l}\text { Levanto - } \\
\text { Yálape } \\
\text { Yálape - Navar }\end{array}$ & $\begin{array}{l}2,5 \\
2,3\end{array}$ & $\begin{array}{c}3 \\
2,5\end{array}$ & Sección & $\begin{array}{l}\text { Calzada empedrada } \\
\text { Escalinatas de piedra } \\
\text { Canales de drenaje }\end{array}$ \\
\hline $\begin{array}{l}\text { Levanto - } \\
\text { Collacruz } \\
\text { Collacruz - } \\
\text { Congona }\end{array}$ & $\begin{array}{l}1,5 \\
0,9\end{array}$ & $\begin{array}{c}2,5 \\
2,5-3\end{array}$ & Sección & $\begin{array}{l}\text { Calzada empedrada } \\
\text { Escalinatas de piedra } \\
\text { Canales de drenaje }\end{array}$ \\
\hline
\end{tabular}

El entorno geográfico en el cual se desenvuelven y proyectan estos caminos está comprendido por laderas empinadas, profundas quebradas y laderas de menor pendiente; además se observan formaciones de roca caliza correspondientes al Cretáceo Superior, con una antigüedad aproximada de 60 millones de años.

Dichos caminos aún se encuentran de regular a buen estado de conservación, presentando cada uno de ellos una tipología diversa, planificada y elaborada en clara armonía con el paisaje que atraviesa y recorre. El primero de estos caminos se desplaza con dirección a la actual ciudad de Chachapoyas; un segundo camino se desplaza con dirección a uno de los principales asentamientos chachapoyas de esta zona denominado Yálape, proyectándose hacia otro asentamiento conocido como Navar; mientras un tercer camino identificado se dirige hacia el poblado de Collacruz, donde se encontrarían los restos de un antiguo tambo construido por los inkas en este lugar, cuyo desplazamiento prosigue hasta la cercanía del sitio arqueológico conocido como Congona. Por último, se visualiza una sección de camino que se desplaza con dirección a la actual localidad de San Isidro del Mayno, que será descrito en otra oportunidad, puesto que por temas logísticos no fue explorado (Figura 2).

\section{Subtramo: Levanto - El Molino - Chachapoyas}

El camino inka que parte de Levanto con dirección a la ciudad actual de Chachapoyas es sin duda, un subtramo particular y de características notables, gracias a su buen estado de conservación, en el cual se han podido identificar y registrar los diversos tipos de camino señalados en la Guía de Identificación y Registro del Proyecto Qhapaq Ñan del Perú (Bar et al. 2016; Ministerio de Cultura 2013). Este camino lo recorrimos parcialmente el año 2008, al ser parte de nuestro reconocimiento de campo, y nuevamente a inicios del año 2017, como parte del trabajo de campo del Proyecto de Investigación Arqueológica con Fines de Conservación y Puesta en Valor: Elaboración de Expediente Técnico para el Proyecto Rehabilitación y Mejoramiento del camino prehispánico Qhapaq Ñan, Chachapoyas - Levanto, Provincia de Chachapoyas, Región Amazonas. Este camino evidencia un buen estado de conservación hasta la localidad de El Molino, con una longitud de $9,5 \mathrm{~km}$ y un ancho que varía entre 2,5 $\mathrm{m}$ a $4 \mathrm{~m}$. Desde El Molino hacia Chachapoyas, el rastro del camino ha sido destruido, pues ha sido pavimentado. Según información recuperada por Aldo Bolaños (2017), el camino se proyecta por la calle Santo Domingo hasta doblar dos cuadras para entrar finalmente a la plaza de armas de Chachapoyas. Entre El Molino y Chachapoyas, la longitud del camino sería de $2 \mathrm{~km}$, aproximadamente. La geografía accidentada de la zona y el medio ambiente húmedo, determinó que se ejecutara la construcción de extensas secciones de calzada empedrada y escalinatas elaboradas con piedra semicanteada, además de escalones tallados en la roca para solucionar la presencia de superficies inestables. Este camino presenta en un $80 \%$ la calzada empedrada (Figura 3), y en pequeñas secciones se ha observado arena como parte de la calzada, siendo su desplazamiento recto y a veces zigzagueante, presentando tanto cuestas hacia arriba como hacia abajo (Figura 4), acorde con la topografía donde se desplaza. También se observan escalinatas y canales de drenaje del tipo abierto (Figura 5), al igual que muros de contención elaborados en algunas secciones donde el camino se desenvuelve. En algunos casos, donde el camino se implementa sobre bofedales, se apreció una calzada elevada alternada con canales de drenaje. Se visualiza, además, el uso indistinto de diferentes tipos de roca en la confección de la calzada, pudiendo ser estas tanto calizas como sedimentarias. 


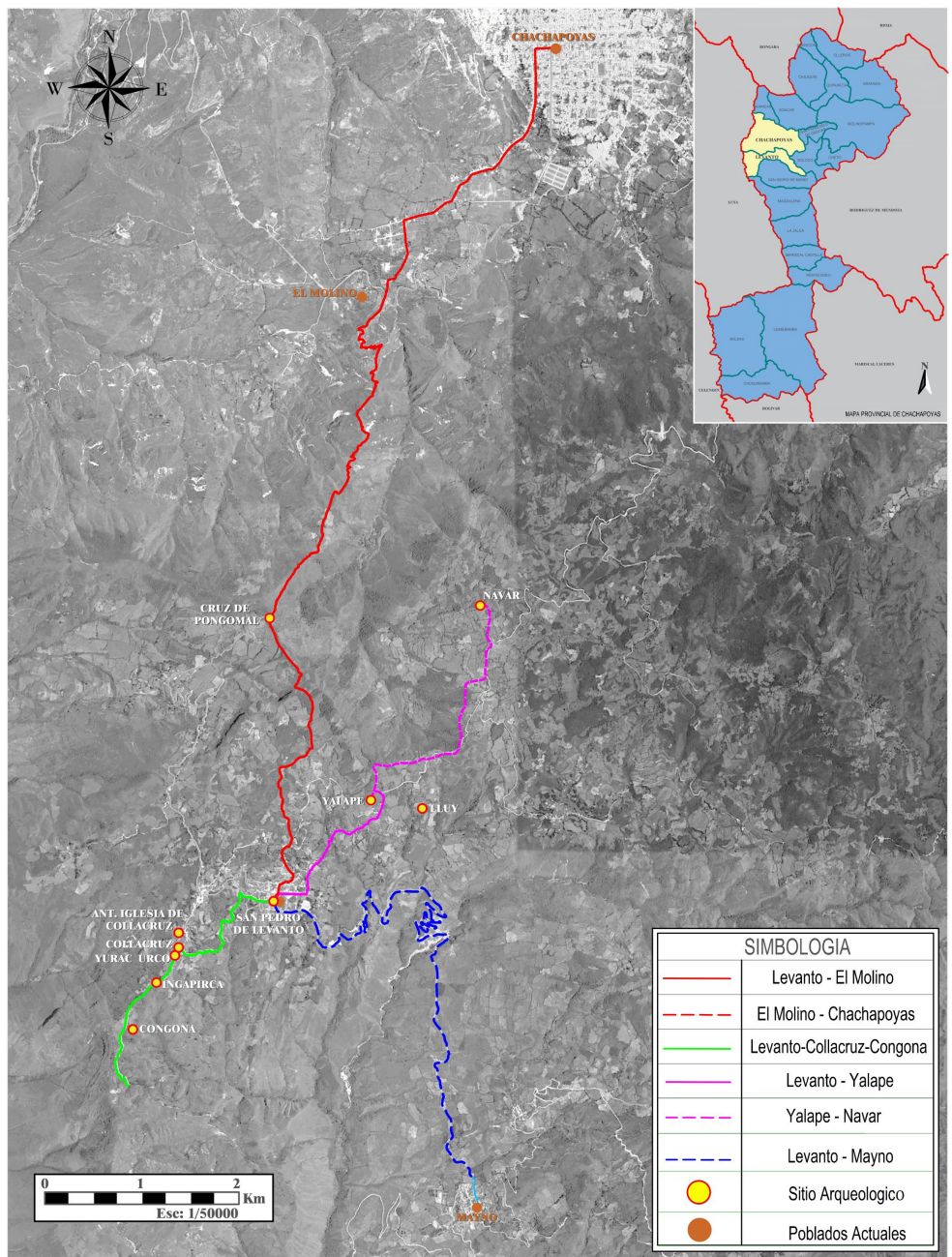

Figura 2. Mapa con el trazado de los caminos y la localización de los sitios arqueológicos del área de estudio.

Map with the layout of the pre-Hispanic roads and the location of the archaeological sites in the study area.

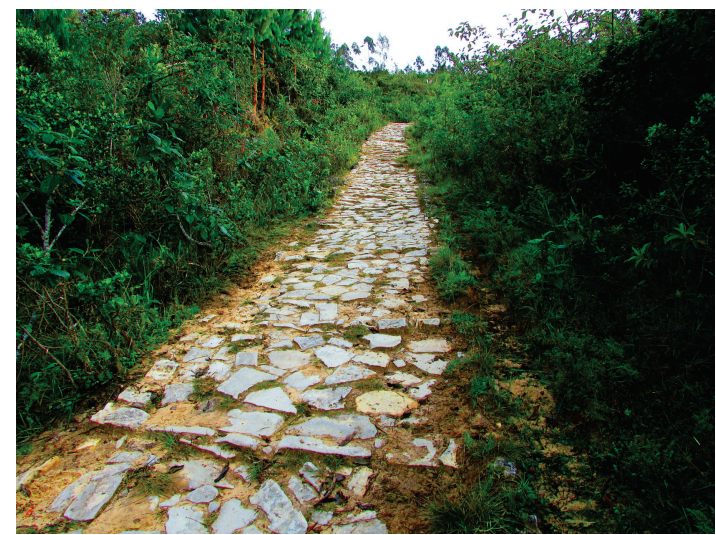

Figura 3. Sección empedrada de camino Levanto - Chachapoyas. Cobbled section of the Levanto - Chachapoyas road.
Durante el recorrido de este subtramo, nos llamó la atención un sitio arqueológico particular conocido como Cruz de Pongomal.

\section{Cruz de Pongomal}

El sitio denominado Cruz de Pongomal está localizada en el cruce de tres caminos distintos, uno en dirección a Collacruz, otro en dirección a Quipachacha y un tercero con dirección a la ciudad de Chachapoyas. Asimismo, está localizado al pie del cerro Pongomal, límite natural entre los distritos de Levanto y Chachapoyas.

El sitio consta de una estructura tipo plataforma, construida a base de piedras que configuran un espacio arquitectónico que visto en planta tiene forma rectangular, y los muros parecen haber sido construidos 


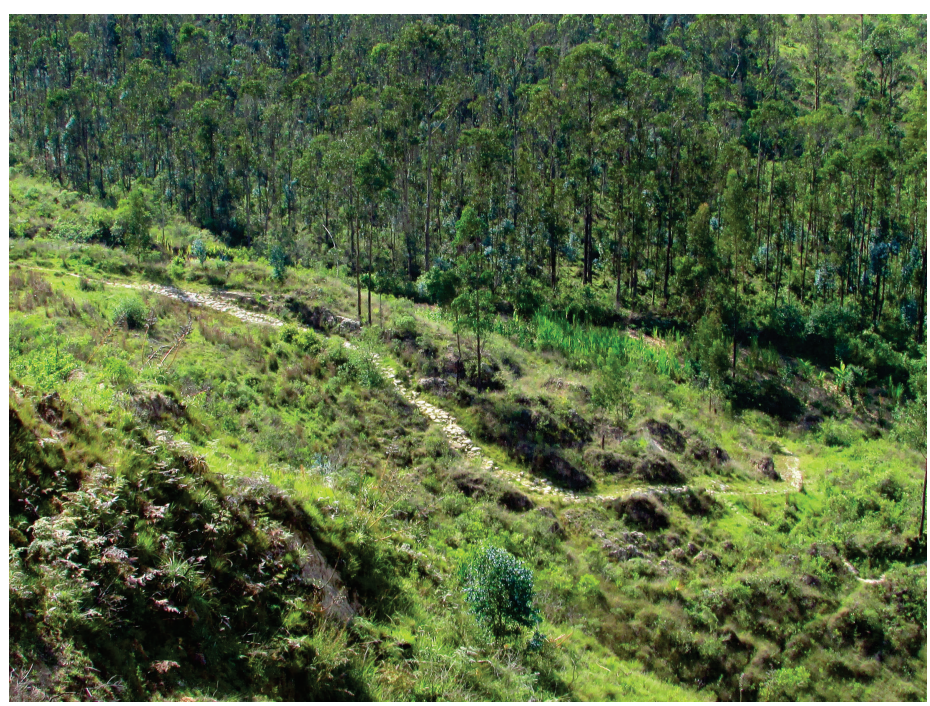

Figura 4. Desplazamiento en zigzag del camino Levanto - Chachapoyas.

Zigzag sections of the Levanto - Chachapoyas road.

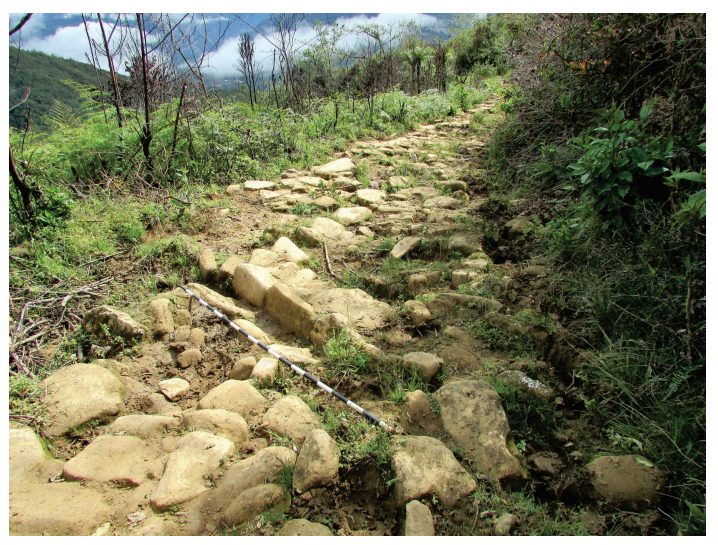

Figura 5. Canal de drenaje, tipo abierto.

Open type drainage channel. alrededor de una gran roca natural localizada al centro de la estructura. La estructura presenta en su fachada siete escalinatas de piedra, siendo la orientación de esta fachada de este a oeste (Figura 6). En la actualidad, en la cima de esta plataforma se reconoce una cruz de madera la que nos puede indicar no solo la función actual de la estructura como un altar católico, sino también deducir su uso en tiempos pretéritos por la arquitectura descrita. Nuestra propuesta funcional, por sus características arquitectónicas y emplazamiento, es que se trataría de un ushnu en el cruce de caminos.

\section{Sección: Levanto - Yálape - Navar}

El segundo camino registrado fue la sección de camino que parte del actual Levanto hacia el sitio

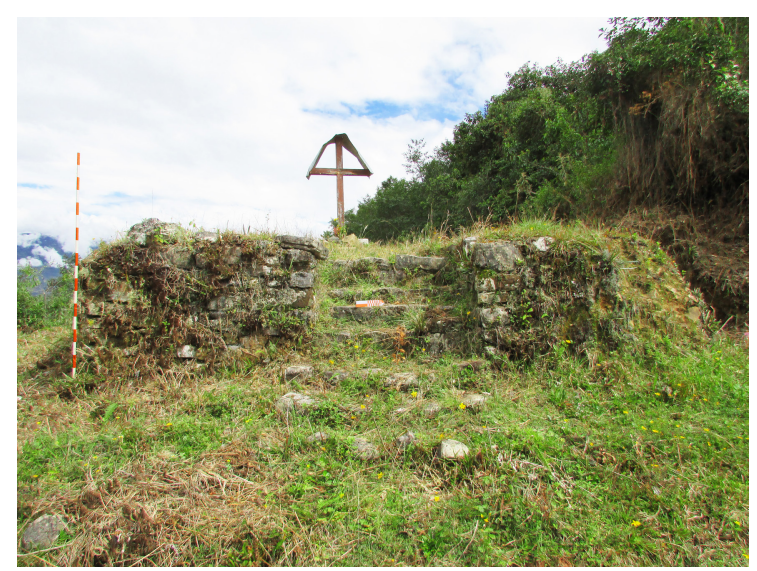

Figura 6. Vista frontal de la estructura arquitectónica de Cruz de Pongomal. Front view of the Cruz de Pongomal architectural structure. 
arqueológico de Yálape, donde se observa el magnífico empedrado del mismo. Su desplazamiento es lineal y a veces zigzagueante (Figura 7), con pequeñas cuestas arriba y cuestas hacia abajo, destacando la presencia de canales de drenaje del tipo abierto; en un solo caso pudimos observar un canal de drenaje del tipo cerrado (Figura 8). Por otro lado, en un segmento del camino en mención, se distingue el trabajo del tallado en roca, localizado en el cruce de un riachuelo llamado Llupcho por los pobladores locales. Esta sección tiene una longitud de 2,5 $\mathrm{km}$ y un ancho promedio de $3 \mathrm{~m}$. De Yálape continua otra sección de camino prehispánico hacia el asentamiento arqueológico de Navar, constituido parcialmente por una calzada empedrada y escalinatas; del que esperamos en algún momento constatar su trayecto completo, forma y estado de conservación. Entre Yálape y Navar, el camino tiene una longitud aproximada de $2,3 \mathrm{~km}$.

\section{Yálape}

El cerro Yálape presenta abundante vegetación propia del bosque nuboso, es de forma alargada y de suaves pendientes, y en su ladera baja se aprecian terrazas modernas. En sus laderas media y superior se evidencia gran cantidad de estructuras arqueológicas, en su mayoría de planta circular, siendo la vegetación de tipo herbácea y arbórea, con abundantes espinas.

Yálape (Ruíz Estrada 2010; Ruíz Barcellos 2006, 2013) es un asentamiento de evidente filiación chachapoyas, localizado en la cima del cerro homónimo. Presenta más de 350 estructuras construidas de piedra tipo pizarrosa, en su gran mayoría de planta circular y dispuestas de forma aglutinada. Dentro de las características arquitectónicas de las estructuras, destacan las plataformas o embasamientos, muchas veces con la presencia de aleros. En algunos muros correspondientes a la parte alta del asentamiento, es destacable el arte desarrollado por los chachapoyas, consistente en frisos en plano relieve de forma romboidal (Figura 9), y formas zigzagueantes divididas en paneles; esta expresión artística es representativa de los asentamientos chachapoyas, pues en otro sitio arqueológico de Levanto, conocido como Lluy, registramos estas mismas figuras. Algunas estructuras de Yálape, vistas en planta, tienen forma rectangular, y estarían asociadas a la ocupación inka del sitio. Esta aseveración se confirmaría con lo señalado por el arqueólogo Ruíz Barcellos, quien encontró "fragmentos de cerámica inka doméstica" durante las excavaciones que efectuara en algunas estructuras de Yálape (Ruíz Barcellos 2006, 2013).

La sección del camino en mención corresponde a un empedrado, por lo general cuesta arriba, combinada con pendientes laterales en zigzag, con drenajes de buena manufactura, debido a que la zona es propensa a

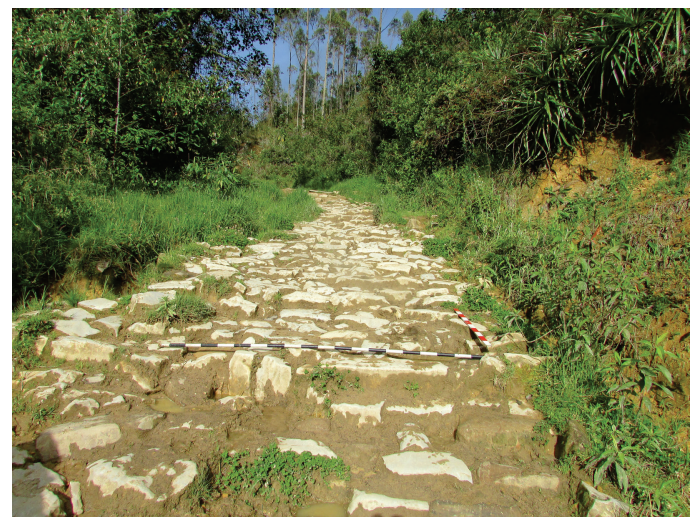

Figura 7. Sección empedrada con peldaños. Camino a Yálape. Cobbled stepped section. Road to Yálape.

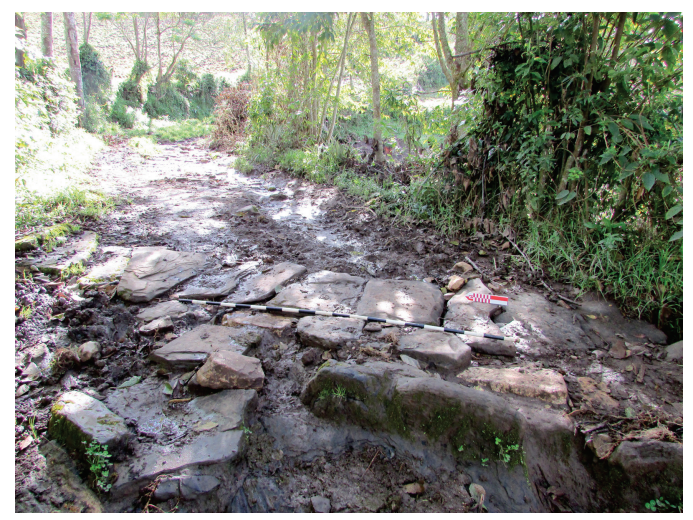

Figura 8. Canal de drenaje, tipo cerrado.

Close type drainage channel.

precipitaciones durante casi todo el año. En esta sección sobresale, además, un afloramiento rocoso que ha sido parcialmente cavado para generar peldaños, bastante similar al registrado por Koschmieder en la provincia de Luya, departamento de Amazonas (Koschmieder 2012:79).

\section{Navar}

Navar es un asentamiento de carácter urbano localizado en la parte alta de una formación rocosa. Compuesto por un gran conjunto de estructuras arquitectónicas construidas con piedras pizarrosas, cubiertas por abundante vegetación, distribuidas en tres sectores: El Sector 1, localizado en la parte sur del asentamiento, está conformado por estructuras de planta circular con aleros, asentadas sobre rocas propias de la zona; estas estructuras se encuentran distribuidas de forma aglutinada, siendo el diámetro de las mismas entre 6 y $8 \mathrm{~m}$. El Sector 2, ubicado al este, conformado por estructuras circulares de $7 \mathrm{~m}$ de diámetro, asentadas sobre embasamientos, distribuidas de forma 
aglutinada y con algunas estructuras pequeñas en forma de "U", compuesta por afloramientos rocosos propios de la zona y piedras canteadas; las medidas de las estructuras son: 1,5 m de largo por $0,9 \mathrm{~m}$ de ancho y 1,8 m de altura máxima; presumimos que estas estructuras pequeñas pudieron cumplir una función funeraria, por el hallazgo superficial de material óseo humano y cerámica fragmentada; estas probables estructuras funerarias se hallan en un nivel inferior a las estructuras circulares, anteriormente descritas. Por último, el Sector 3,

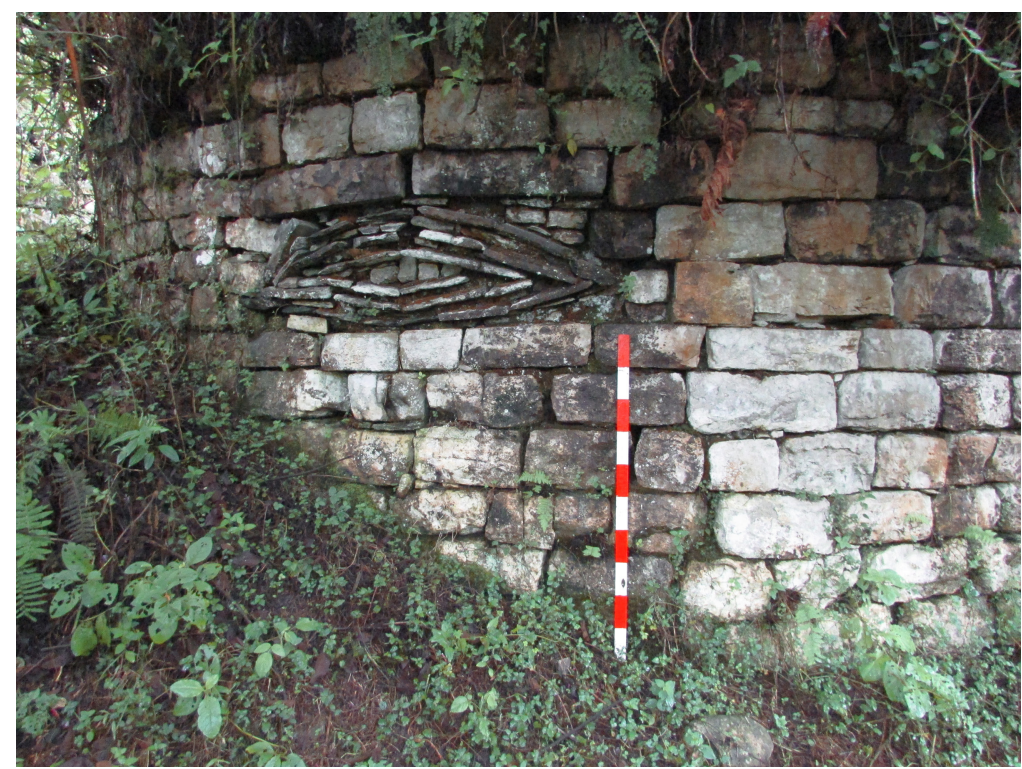

Figura 9. Recinto circular, detalle de arte mural chachapoyas en Yálape.

Circular enclosure. Detail of Chachapoyas mural art in Yálape.

localizado hacia el norte, está constituido por estructuras de planta circular dispersas, cuyo diámetro varía entre los 8 y 12 m de diámetro, asentadas sobre embasamientos y distribuidas a desnivel, conectadas por pequeños peldaños a manera de escalinatas. La mayor cantidad de estructuras se encuentran en este último sector. En los tres sectores descritos se ha encontrado cerámica fragmentada, perteneciente al grupo cultural chachapoyas.

\section{Sección: Levanto - Collacruz - Congona}

La tercera vía registrada es un segmento de camino que unía Levanto con el poblado de Collacruz. Dicha vía es bastante fácil de recorrer, pues no presenta los dificultosos accidentes geográficos de los caminos previamente detallados. Se desplaza ligeramente recto siguiendo la topografía del terreno, con calzada empedrada (Figura 10) y algunos peldaños en mal estado de conservación; presenta una longitud de $1,5 \mathrm{~km}$, y un ancho promedio de 2,5 m. En esta sección son patentes las mayores evidencias de infraestructura construida por los inkas en Levanto: un sitio con estructuras de piedra, de planta rectangular, que configurarían un pequeño tampu inkaico conocido en la actualidad como Collacruz; una estructura inka modificada en tiempos iniciales de la Colonia llamada Yurac Urco; un espacio arquitectónico de piedras modificado, pero con claros indicios de ser un edificio prehispánico, conocido como la Iglesia Antigua de Collacruz; un recinto de planta rectangular del tipo kallanka conocido como Congona; y estructuras construidas con piedra pizarrosa formando construcciones rectangulares llamado Ingapirka.

Debemos señalar que se observa la continuación de esta sección saliendo de Collacruz, con dirección al sitio de La Congona, proyectándose el mismo por $900 \mathrm{~m}$ de calzada empedrada.

\section{Collacruz}

Sitio arqueológico descrito por Morgan Davis (1996) e identificado por Montoya et al. (2003) como el tambo de Levanto. Se trata de un conjunto de recintos de planta rectangular y cuadrangular distribuidos de forma planificada alrededor de un patio, elaborados con piedras regulares de buena manufactura (Figura 11). Dentro de los recintos destaca una estructura de forma rectangular, cuyas dimensiones son 13,5 $\mathrm{m}$ de largo y un ancho de $8 \mathrm{~m}$, siendo de $1,2 \mathrm{~m}$ la altura promedio de esta estructura. Lamentablemente, este asentamiento se encuentra cubierto por vegetación y ha sido afectado por la presencia de ganado vacuno.

\section{Yurac Urco}

En el segmento en cuestión, muy cerca del poblado actual de Collacruz, se encuentra el sitio de Yurac Urco, 


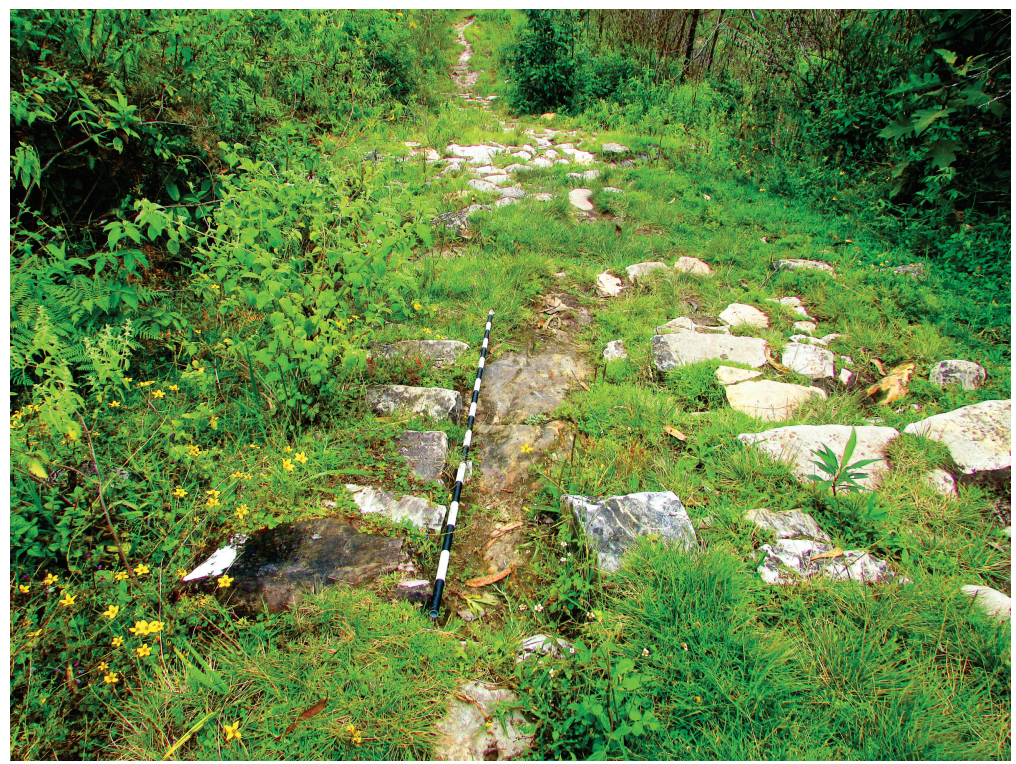

Figura 10. Sección empedrada de camino Levanto- Collacruz.

Cobbled section of the Levanto - Collacruz road.

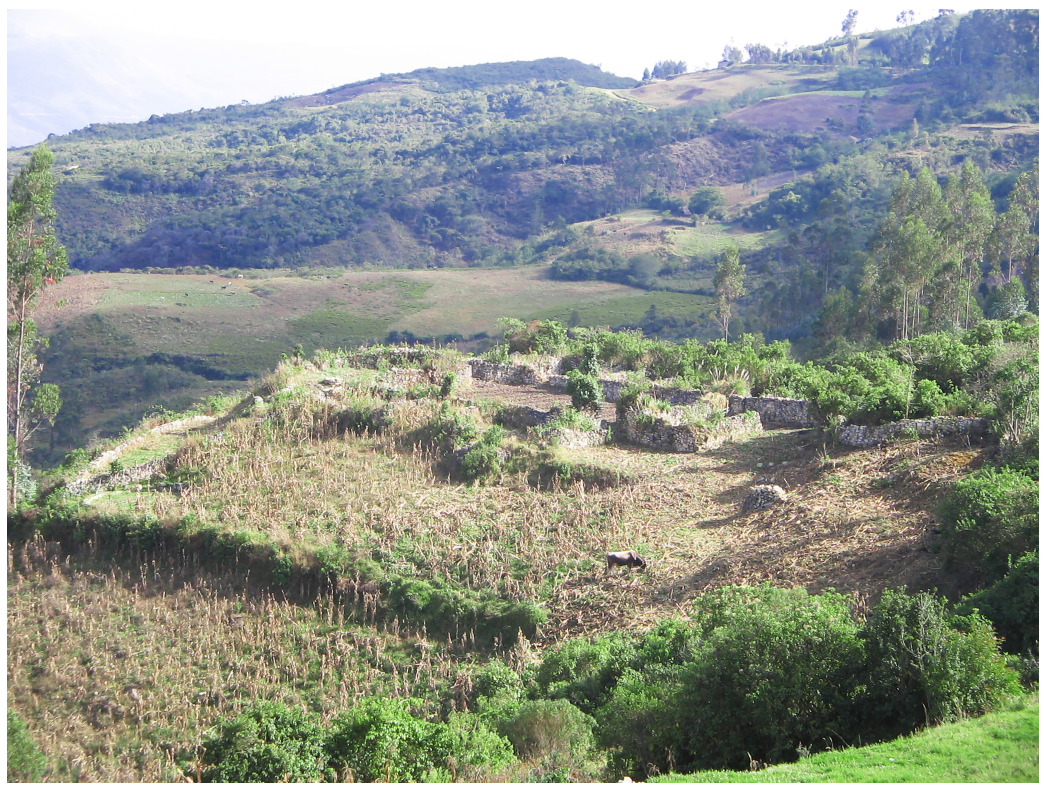

Figura 11. Vista panorámica del sitio arqueológico de Collacruz.

Panoramic view of the Collacruz archaeological site. 
trabajado por el arqueólogo canadiense Morgan Davis. Consta de una estructura circular chachapoyas post-inka, restaurada por Davis en 1992, de 8,5 m de diámetro externo, cuyo muro fue hecho con bloques de roca caliza, dispuestos en hiladas horizontales, alcanzando 3,5 m de alto, con un techo cónico de paja (Figura 12), presentando un vano de acceso hacia el oeste; dicha estructura fue levantada encima de un muro ligeramente curvo de más de $20 \mathrm{~m}$ de largo y una altura máxima de 2,5 m (Figura 13), construido con piedras regulares, primorosamente labradas y de clara filiación inka (Davis 1996:20). Quizá el muro curvo de Yurac Urco pueda corresponder a un recinto ceremonial inka, que fue desmantelado en los inicios de la Colonia, al ser los chachapoyas aliados de los españoles, siendo reutilizado luego como muro de sostenimiento para la construcción de la estructura circular que Davis encuentra y restaura en 1992. La estructura arqueológica se encuentra en regular estado de conservación, ya que es un atractivo turístico de la región, visitado regularmente.

\section{Antigua Iglesia de Collacruz}

Se observan tres recintos de planta rectangular, construidos a base de piedras canteadas. Tanto la fachada frontal como las fachadas laterales se encuentran cubiertas por maizales y calabazas que dificultan su visibilidad. El ancho de los muros es de $0,6 \mathrm{~m}$; en uno de los recintos se distinguió un vano de acceso rectangular. Al interior de uno de los recintos se localizaron dos pequeños nichos de forma rectangular, cuyas medidas son $0,6 \mathrm{~m}$ de largo por $0,4 \mathrm{~m}$ de alto y $0,3 \mathrm{~m}$ de profundidad. Por las características arquitectónicas señaladas, particularmente la planta rectangular de los edificios descritos, consideramos que el sitio es de filiación inka.

\section{Congona}

En dirección sureste, a escasos metros de esta sección de camino, reportamos otra estructura de clara manufactura inka, conocida como Congona. Corresponde a un edificio de $32 \mathrm{~m}$ de largo por $9 \mathrm{~m}$ de ancho y una altura promedio de 2,3 m; construido con piedras tipo pizarrosa y presencia de hornacinas trapezoidales. No tenemos certeza acerca de la cantidad de hornacinas que existían, ya que el muro que las sostenía se encuentra deteriorado, pero aún se distinguen seis nichos en regular estado de conservación (Figura 14); indudablemente, la estructura responde a una estructura típica del patrón arquitectónico inka, conocido como kallanka.

\section{Ingapirka}

Está conformado por estructuras arquitectónicas a ambos lados del camino proveniente de Collacruz. Se visualizan muros de piedra utilizados para contención y

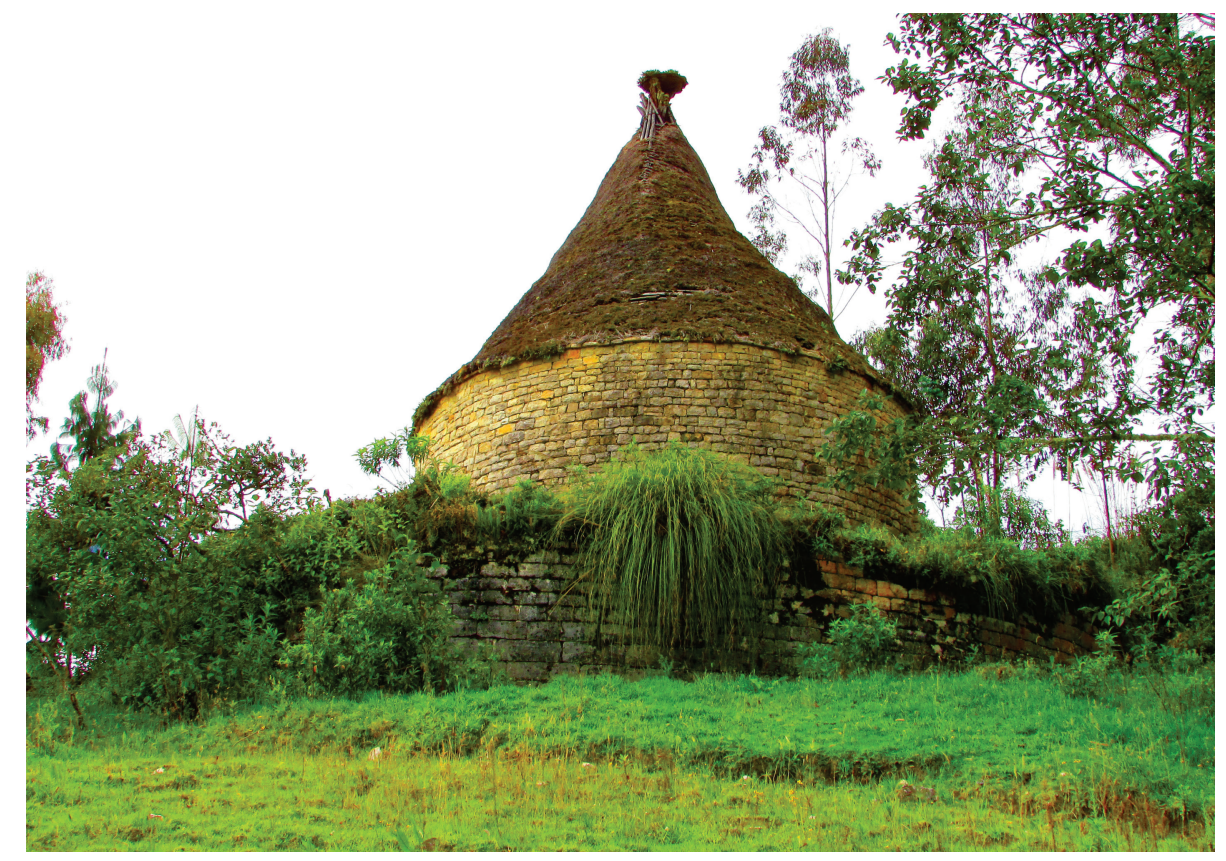

Figura 12. Superposición de muros en el sitio de Yurac-Urco.

Wall overlapping at the Yurac-Urco site. 


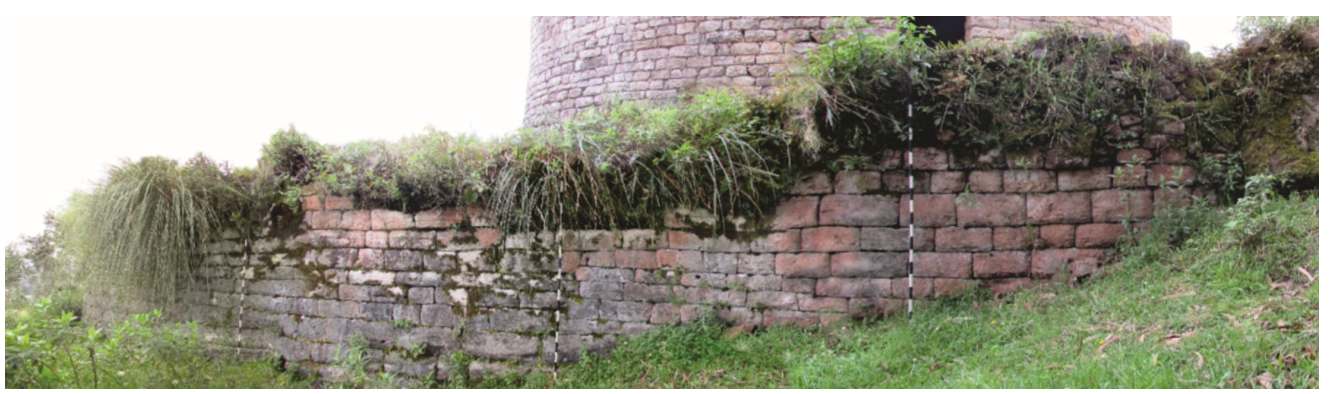

Figura 13. Detalle del muro curvo inka de Yurac - Urco.

Detail of the inka curved wall of Yurac - Urco.

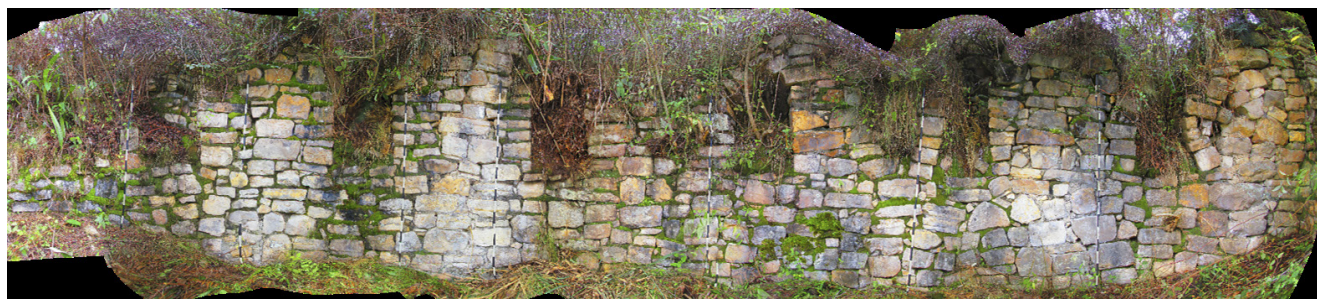

Figura 14. Detalle del muro con hornacinas trapezoidales en el sitio de Congona.

Detail of the wall with trapezoidal niches at the Congona site.

algunas estructuras de planta rectangular y circular sobre estos (Figura 15). Los muros son de piedra pizarrosa y están cubiertos por densa vegetación. Las paredes de contención poseen una altura promedio de $3,5 \mathrm{~m}$, que, a su vez, sostienen estructuras rectangulares. Algunos de estos recintos miden $6 \mathrm{~m}$ de largo por 3,8 $\mathrm{m}$ de ancho y con una altura de $2 \mathrm{~m}$. Determinadas estructuras se encuentran destruidas, principalmente por la expansión agrícola. El sitio combina estructuras chachapoyas e inka.

Respecto a las vías de comunicación reconocidas, sostenemos que hubo una clara adaptación de ellas a la topografía existente, configurándose los caminos en una parte del paisaje geográfico por el cual se desplazaron. Estas vías fueron obras de infraestructura que una sociedad como la de los chachapoyas implementó antes de los inkas, al igual que otras sociedades prehispánicas (moche, wari, tiwanaku, chimú). Por ejemplo, Koschmieder, deja en claro la existencia de dos caminos prehispánicos durante sus trabajos en Luya, que unen asentamientos, sitios funerarios y terrazas de cultivo de distintiva ocupación chachapoyas (Koschmieder 2012:79). En nuestro caso, el camino observado entre Yálape y Navar, nos estaría demostrando la conexión de estos dos importantes asentamientos de adscripción cultural chachapoyas.

Estas apreciaciones nos llevarían a plantear que los caminos de Levanto podrían haber sido construidos antes de la llegada de los inkas a esta región, no obstante, el enunciado aún requiere de mayores estudios y corroboración de carácter arqueológico.

Como se ha señalado más arriba, Levanto fue un antiguo asentamiento preinkaico e inka, donde se han reportado hasta cuatro caminos que parten de esta antigua llaqta. Los caminos descritos no varían mucho en cuanto ancho, variedad de material constructivo empleado, adaptación del paisaje y elementos arquitectónicos presentes, lo que sugeriría que, si dichos caminos fueron realizados por los chachapoyas, también podrían haber sido utilizados y remodelados durante el proceso de integración y reestructuración llevado a cabo por los inkas en el territorio conquistado.

\section{Levanto y las Construcciones Inkas}

El pueblo actual de San Pedro de Levanto presenta varias construcciones de piedra en los alrededores de su plaza principal, que nos hablan de un antiguo emplazamiento. Posiblemente dichas construcciones nos remiten a la ocupación de los inkas descrita en los documentos etnohistóricos, donde se asegura que Túpac Yupanqui dejó hijos y bisnietos en este asentamiento, donde tenían chacras y tierras (Lerche 1995:108; Schjellerup 2005:144). 


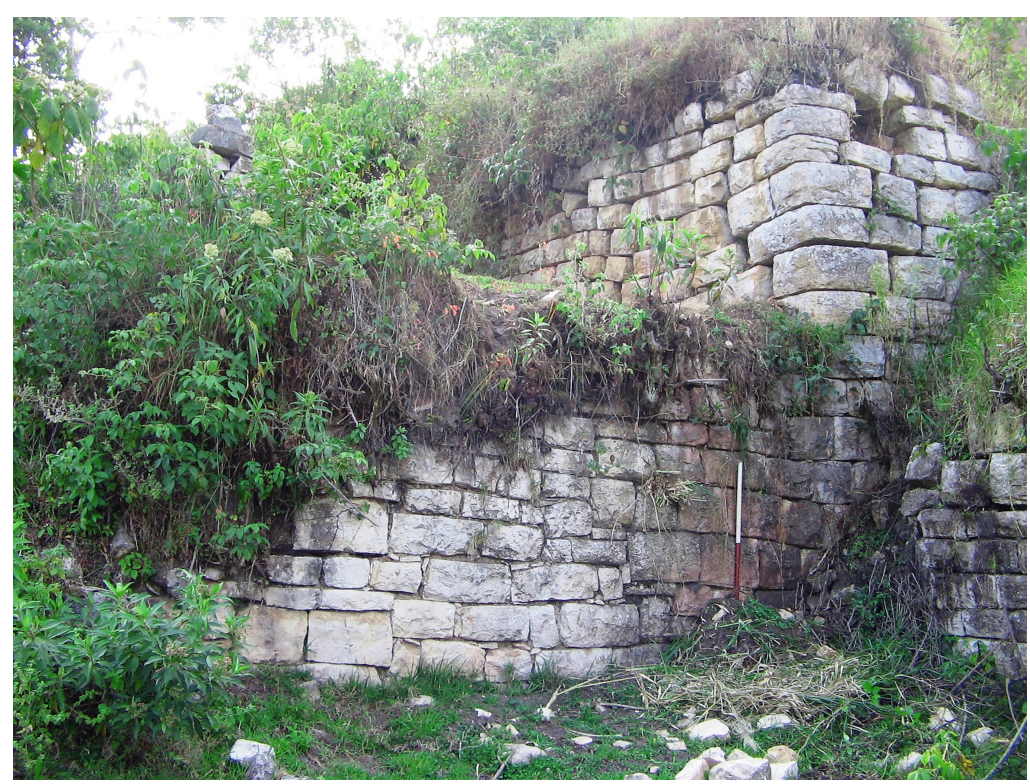

Figura 15. Sección de muros rectos de planta rectangular en Ingapirka.

Section of straight walls of rectangular plan in Ingapirka.

Los sitios asignados en este trabajo a los inkas (1470-1532 DC), responden mayormente a obras de infraestructura que forman parte de la estrategia de dominación implantada por los inkas a lo largo de las provincias anexadas al Tawantinsuyu.

En el caso de Yálape, queda demostrada la ocupación inka con la presencia de estructuras de forma rectangular en la parte alta del asentamiento, además de la existencia de "cerámica doméstica inkaica" (Ruiz 2013). Collacruz es un asentamiento prehispánico, del cual queda muy poco, porque en la actualidad se encuentra un poblado moderno asentado en gran parte del sitio, sin embargo, los recintos que aún subsisten obedecen al patrón constructivo inka. En opinión del arqueólogo Morgan Davis, quien realizó trabajos en Yurac Urco, "Collacruz fue una pequeña llajta, probablemente una estancia de camino o largo tambo usado para trasladar tributos, armas o mitmajcunas" (Davis 1996:24 [la traducción es mía]).

Tomando en cuenta lo antes mencionado, consideramos que tanto Collacruz como Yurac Urco formaron parte del mismo asentamiento, dada la cercanía y las características del patrón arquitectónico inka expuesto, siendo la separación entre ambos asentamientos de solo $80 \mathrm{~m}$ lineales. Es probable que corresponda a un asentamiento a manera de tатри real o inkawasi.

El sitio de Yurac Urco, erigido sobre un promontorio natural, constituido por dos estructuras, una encima de la otra, donde el primer recinto (recinto superior) fue totalmente restaurado durante los trabajos dirigidos por Morgan Davis en 1992, mientras que la segunda estructura (estructura inferior) presenta una indudable manufactura inka (muro curvo construido con rocas labradas y pulidas colocadas primorosamente), que debió haber formado parte de una importante construcción de carácter ceremonial. Lamentablemente, Davis no menciona el hallazgo de material cerámico asociado durante su trabajo.

La antigua iglesia de Collacruz también parece reforzar la idea de que Collacruz pueda ser más que un sitio, debido también a su colindancia; sin duda, excavaciones futuras en el lugar podrían ayudarnos a corroborar esta propuesta.

En el caso de Congona tenemos un claro ejemplo de una estructura tipo kallanka con hornacinas trapezoidales, cuya función fue, tal vez, servir de tambo, por su cercanía al segmento de camino inka Levanto Collacruz.

En Levanto quedan todavía numerosos sitios de evidente filiación inka por investigar, como Condechaca, el famoso canal de Allpachaca o Ashpachaca, Machuhuasi y Rumsirge (Gates 1997). En este contexto, el presente ensayo representa una primera aproximación a la infraestructura caminera de Levanto y la ocupación inka, desde sus principales asentamientos. A partir de lo expuesto, esperamos en un futuro próximo efectuar un trabajo de mayor envergadura, que posibilite un mayor acercamiento a la estrategia de dominación empleada por los inkas, así como establecer plenamente las diferencias entre un camino chachapoyas de otro inkaico. Ciertamente, el propósito investigativo de este trabajo como de otros que presentemos más adelante, es aportar al conocimiento sobre el importante rol desarrollado por 
Levanto, como parte de la provincia de los chachapoyas durante el funcionamiento del Tawantinsuyu.

\section{Comentarios Finales}

La documentación etnohistórica sobre Levanto es variada y profusa, y atestigua lo relevante que fue este lugar en la época preinkaica, al ser uno de los asentamientos más importantes de los chachapoyas. En 1470 DC aproximadamente fue tomada por los inkas para convertirse en la capital de una de las provincias inkas en esta apartada zona del Chinchaysuyu. Ya en tiempos de la Colonia, fue utilizada para constituirse en el segundo emplazamiento de la ciudad de San Juan de la Frontera de los Chachapoyas en 1538.

A nivel arqueológico, la Coordinación de Investigación y Registro de la Red Vial Inca del Proyecto Qhapaq Nan (Bar et al. 2016) ha planteado la existencia de otro camino longitudinal, denominándolo camino longitudinal de la selva. Su construcción se habría iniciado durante el gobierno de Túpac Yupanqui, alcanzando una longitud aproximada de $470 \mathrm{~km}$, desplazándose desde el centro administrativo de Huánuco Pampa hasta el tambo de Levanto. Dicho camino se conectaba con el camino longitudinal de la sierra mediante distintos caminos transversales. $\mathrm{Al}$ parecer, el camino señalado fue "construido con fines militares", según el explorador Víctor von Hagen (1971:190), aunque es una hipótesis que necesita ser analizada a nivel regional y macro-regional.

Según las referencias dadas por los pobladores actuales, tanto de la comunidad campesina de Levanto como la de Quipachacha, en cuyos territorios se encuentran los caminos descritos, se realizaban de forma conjunta faenas comunales de mantenimiento, limpieza y arreglo de los pavimentos y empedrados de los caminos. No obstante, el sistema constructivo observado nos remite a los constructores originales de los caminos, señalándonos que los diferentes tipos de caminos fueron parte de un diseño correspondiente a un patrón constructivo prehispánico, aun cuando hoy en día no se conserve el conjunto de características arqueológicas originales (Bolaños 2017; Campos 2017). Pese a lo anterior, definir la impronta cultural de los caminos es extremadamente complejo, porque los trazos viales no se abandonan completamente y los caminos se ocupan por largos periodos, siendo frecuentemente limpiados, mantenidos y remodelados por las comunidades locales, como lo hemos documentado. Evidentemente, es más sencillo mantener un camino existente, que aperturar una nueva sección de vía, pero subrayamos que, en términos generales, la activación de los caminos reconocidos en Levanto y dados a conocer en este trabajo, es definitivamente prehispánica, por las características ya indicadas.

Desde una amplia perspectiva, afirmamos con cierto grado de confiabilidad que Levanto fue en tiempos del Inka un imprescindible centro y nodo para el arribo de funcionarios, soldados y mitmaqkuna a esta zona alejada del Chinchaysuyu inkaico, el que fue utilizado posteriormente por los colonizadores españoles y que siguió siendo empleado durante el Virreinato.

Finalmente recalcamos que, con el transcurso del tiempo, los caminos de Levanto han sido objeto de un uso intensivo y de diferentes intervenciones de mantenimiento por parte de las comunidades que se encuentran a sus alrededores. Las vías de Levanto son una pequeña muestra de los caminos que aún subsisten y vencen el tiempo, son los caminos de los pueblos olvidados del Antiguo Perú, entre los que destacan, los caminos del antiguo Tawantinsuyu. Estos caminos unen, comunican, transportan y sobre todo sirven para que aun persista y subsista nuestra identidad como pueblos ancestrales. El camino del Inka o Qhapaq Ñan, la evidencia vial más extensa e importante de América precolombina, nos permite afirmar que el hombre andino fue capaz de transformar la naturaleza que lo rodeaba sin explotarla en demasía, permitiendo que sea parte de un paisaje cultural que podemos contemplar hoy, más de 500 años después.

Agradecimientos: A los evaluadores externos de Chungara que permitieron enriquecer este ensayo con sus comentarios. Un agradecimiento a Anthony Villar por la bibliografía proporcionada. Gracias a Sandra Cubas por la asistencia en campo y la ayuda desinteresada; mi agradecimiento también va para Abel Cisneros por la ayuda proporcionada con la digitalización de planos asimismo, agradezco a mi hermano Juan Campos por la ayuda con la traducción del resumen. Finalmente, a los colegas Carlos González y Christian Vitry por invitarme a ser parte del "Qhapaq $\tilde{N} a n$ II, Taller Internacional en torno al Sistema Vial Inkaico".

\section{Referencias Citadas}

Bar, A., J. Bernabé, M. Cabrera y G. Casaverde 2016. Guía de Identificación y Registro del Qhapaq Ñan. Segunda edición, Ministerio de Cultura del Perú, Lima.
Bolaños, A. 2017. Informe Final del Proyecto de Investigación Arqueológica con Fines de Conservación y Puesta en Valor: Elaboración de Expediente Técnico para el Proyecto Rehabilitación y Mejoramiento 
del camino prehispánico Qhapaq Ñan, Chachapoyas - Levanto, Provincia de Chachapoyas, Región Amazonas, Lima.

Brack, A. 2006. Ecología. Empresa Editora El Comercio S. A., Lima.

Cabello Balboa, M. 1951 [1586]. Miscelánea Antártica, una Historia del Perú Antiguo. Universidad Nacional Mayor de San Marcos, Instituto de Etnología, Lima.

Caja, C. y W. Díaz 2006. Reconocimiento y Registro del Entorno Territorial del Qhapaq Ñan. (Volumen IV) El Qhapaq Nan en la Ruta del Chinchaysuyu entre Pías y Chachapoyas. Instituto Nacional de Cultura, Lima.

Campos, C. 2008. Informe Final del Proyecto de Inventario y Registro del Patrimonio Cultural de la Nación. Campaña 2008, Región Amazonas, Lima.

Campos, C. 2017. Informe del Reconocimiento Arqueológico del Camino Prehispánico Qhapaq Ñan, Chachapoyas - Levanto - Yálape, Provincia de Chachapoyas, Región Amazonas, Lima.

Cieza de León, P. 1984 (1553). Crónica del Perú. Editorial PEISA, Lima.

Cieza de León, P. 1986 [1553]. Crónica del Perú: Segunda Parte. Fondo Editorial de la Pontificia Universidad Católica del Perú / Academia Nacional de Historia, Lima.

Davis, M. 1988. Chachapoyas; The Cloud People. Additions, Corrections, and Selected Themes. Department of Native Studies, University of Sudbury, Ontario.

Davis, M. 1996. La Casa Redonda and Yurac-Urco, Two Round Houses in Department Amazonas, Peru. A Report on an Archaeological Reconstruction Done by the Community of Collacruz in 1992. Publication Jéremie, Ontario.

Espinoza, W. 1967. Los señoríos étnicos de Chachapoyas y la alianza hispano-chacha. Revista Histórica XXX:224-333.

Gates, C. 1997. La Historia Inédita de los Chachapoyas, Descendientes de los Constructores de la Fortaleza de Kuélap. Universidad de San Martín de Porres, Lima.

Garcilaso de la Vega, I. 1991 [1609]. Comentarios Reales de los Incas. Fondo de Cultura Económica, México D.F.

Guillén, S. 2002. Las momias de la laguna de los Cóndores. En Chachapoyas, El Reino Perdido, editado por E. Gonzáles y R. León, pp. 345-387. AFP Integra, Lima.

Hagen, V. 1971. El Imperio de los Incas. Editorial Diana, México D.F.

Hyslop, J. 1992. Qhapaq Ñan. El Sistema Vial Inkaico. Traducido por E. Arias. Instituto Andino de Estudios Arqueológicos y Petróleos del Perú, Lima.

Kauffmann, F. 2013. Los Chachapoyas: trayectoria cultural. En Los Chachapoyas, editado por F. Kauffmann, pp. 41-65. Banco de Crédito del Perú, Lima.

Kauffmann, F. y G. Ligabue 2003. Los Chachapoya(s) Moradores Ancestrales de los Andes Amazónicos Peruanos. Universidad Alas Peruanas, Lima.
Koschmieder, K. 2012. Jucusbamba: Investigaciones Arqueológicas y Motivos Chachapoya en el Norte de la Provincia de Luya, Departamento de Amazonas, Perú. Ministerio de Agrícultura, Lima.

Lerche, P. 1995. Los Chachapoya y los Símbolos de su Historia. Lima. Lerche, P. 1996. Chachapoyas. Guía de Viajeros. Intigráfica, Lima.

Ministerio de Cultura 2013. Guía de Identificación y Registro del Qhapaq Ñan. Primera edición, Ministerio de Cultura del Perú, Lima.

Montoya, M., R. Díaz y W. Araujo 2003. Informe Final del Tramo Exploración: Amazonas-San Martín, Piura-Cajamarca. Instituto Nacional de Cultura. Proyecto Integral Qhapaq Nan. Levantamiento de Información del Sistema Vial Inca. Macro Región Norte, Lima.

Murúa, M. 2001 [1613]. Historia General del Perú. Editado por M. Ballesteros, Serie Crónicas de América, Historia 16 Madrid.

Narváez, A. 1988. Kuélap: una Ciudad Fortificada en los Andes Nor-Orientales de Amazonas, Perú. En Simposium Arquitectura y Arqueología: pasado y futuro de la construcción en el Perú, editado por V. Rangel, pp.115-142. CONCYTEC, Chiclayo.

Narváez, A. 2013. Kuélap: centro del poder político de los Chachapoyas. En Los Chachapoyas editado por F. Kauffmann, pp. 87-159. Banco de Crédito del Perú, Lima.

Reichlen, H. y P. Reichlen 1950. Recherches archaéologiques dans les Andes du haut Utcubamba. Deuxième rapport de la Mission Ethnologique Française au Pérou septentrional. Journal de la Société des Américanistes 39:219-246.

Rivera Serna, R. 1955. Libro Primero de Cabildos de la Ciudad de San Juan de la Frontera de Chachapoyas. Fénix, Revista de la Biblioteca Nacional 11:292-330.

Ruíz Barcellos, J. 2006. Informe Final del Proyecto de Investigación, Conservación y Acondicionamiento Turístico del sitio arqueológico de Yalape- Levanto, I Etapa. Informe presentado al Instituto Nacional de Cultura, Lima.

Ruíz Barcellos, J. 2013. Purún Llacta y Yálape: dos miradas para Kuélap. En Los Chachapoyas, editado por F. Kauffmann, pp. 214-219. Banco de Crédito del Perú, Lima.

Ruíz Estrada, A. 2010. Amazonas, Arqueología e Historia. Universidad Alas Peruanas, Lima.

Schjellerup, I. 2002. Reflexiones sobre los Chachapoya en el Chinchaysuyu. Boletín de Arqueología PUCP 6:43-56.

Schjellerup, I. 2005. Incas y Españoles en la Conquista de los Chachapoya. Fondo Editorial de la Pontificia Universidad Católica del Perú - Instituto Francés de Estudios Andinos, Lima.

Schjellerup, I. 2017. La provincia inka de Chachapoyas. Boletín de Arqueología PUCP 23:259-281. 